\title{
METACOGNITIVE STRATEGIES: ASSET TO EFFICIENT LEARNING AND EDUCATION
}

\author{
Pavel Doulik - Jiri Skoda - Jaroslav Rican
}

DOI: 10.18355/PG.2015.4.1.62-81

\begin{abstract}
The following text deals with the metacognitive strategies. All authors introduce readers into the metacognition terminology and knowledge and describe in detail contemporary trends in the field of metacognitive strategy research. Authors acquaint the reader to the current findings of empirical researches and also they point out the importance of the elementary implementation of metacognitive activities into the educational process.
\end{abstract}

\section{Key words}

metacognition, metacognitive strategies, comprehension strategies, problem solving strategies

\section{Introduction}

"Rapidly changing world thanks to the technological advance produces new and unknown situations for the human being and society, to which it is necessary to adapt "(Ignacio - Nieto - Barona, 2006: 16). Contemporary world is going through series of dynamic changes which have, due to technological advance, impact also on the society. If a certain individual wants to be part of the society, he/she has no other choice, but to adapt to these changes. The level of adaptation is a result of inner and outer factors (which constantly recreate and interact with each other). The goal of education is to prepare each individual within the society to be able to adapt to these changes and also to equip each individual with abilities necessary to face the requirements successfully. Education is therefore one of the most important modern social priorities imbedded within the legislative and international systems and institutions where competent staff members have to deal with the level of adaptation to this resort and what resources will be given towards these issues (Obama hits the road to push for education reforms, 2013; OECD, 2013; China’s \$250 Billion Education Budget, 2013). The main issue researched in this article is not only the importance of the education itself. The postmodern situation of (but not only) the western world deals with the question; in what scale can we guarantee the quality of such education, where all the parts of a modern human being are cultivated in its "organic" and "complex" nature (Habl, 2012) and this also deals with how this may help to develop the feedback of this anthropomorphic potential. ${ }^{1}$

In the recent time a different education approach has been observed which managed to cover the aspects of goal-directed and individually tailored education and also managed to gradually pass on the pupil/student the sence of responsibility for their learning. The study of metacognition has given to 
many experts in the field of education the key to a new dimension of a student's potential which needs to be examined in detail.

So far we have discovered very little about the process of how individuals go from the rather passive and unintended usage of strategies, to active and towards-the-goal-aimed usage which can be more frequently observed among older and more experienced students and especially adults. (Waters Schneider, 2009). The proper use of metacognition shows undeniable trend towards understanding and describing suspected and unsuspected possibilities in education.

\section{Metacognition}

Metacognition is usually described as thought process of thinking (Lai, 2011), or as the knowledge of control over the inner cognitive activities during the learning process, therefore we are more likely to gain and use already known knowledge of the cognitive processes themselves and their predispositions, plus their ability to alter, improve and develop these processes and predispositions (Helus - Pavelkova, 1992). Cognition can be therefore defined as a complex of psychological processes of information elaboration - this way we can (in the relation to metacognition) characterize metacognition as an "object" which is administrated by metacognitive processes on its specific level. A point of view where metacognition and cognition can be differentiated is described by J. Garofalo and F. Lester (1985): “it's necessary to perceive cognition as a process that is connected to the performance process, unlike metacognition which administrates the selection and planning of such things, which are needed to be done and then, it monitors what is progress right now" (1985: 164). However, it is very hard to exactly differ these two terms from each other. Some authors referred to this construct as to a e.g.: reflexive abstraction (Piaget -Wedgwood Blanchet, 1976), or to a reflexive intelligence (Skemp, 1979). The concept of metacognition was first used by developmental psychologists and it is today well discussed and applied in the field of clinical psychology, experimental psychology, cognitive neurosciences and mainly by educational psychology.

J. Flavell (1979), who is said to be the author of the original term "metacognition", divided metacognition into two elementary components: cognitive knowledge and cognitive regulation/monitoring. The knowledge of cognition contains quite ordered set of knowledge about our own-self (personal) characteristics (strong and weak features of cognition), knowledge of strategies and required tasks (assignment characteristics and the requirements of the assignment/task situation based on the analogy of previous experience). This cognition also contains the knowledge of "know how to do things", when to do them and when is the best time and conditions to apply individual strategy. G. Schrawa's, K. J. Crippen's and K. Hetley's (2006) division is the most commonly used nowadays. They divide this subcomponent of metacognition into declarative knowledge, procedural knowledge and conditional knowledge.

Metacognition is a multidimensional construct, which is related to important concepts such as motivation (Zimmerman, 1995; Borkowski, Chan \& Muthukrishna, 2000), critical thinking (Kuhn, 1999), problem 
solving (Flavell, 1976), learning strategies (Cap - Mares, 2001), or autoregulated learning (Boekaerts, 1997; Zimmeman, 2002). The relation of the last mentioned concept to metacognition is not well defined up to this day, even though it is still being discussed, whether autoregulated learning is primary or secondary to metacognition. Theoretical experts in the field of autoregulated learning and metacognition state a consensus, which says that during the development of metacognition the level of autoregulation increases as well. According to one of the leading authors of the autoregulated learning concepts ${ }^{1}$, B. J. Zimmerman (2000), self-feedback has the central role in order to reach higher level of autoregulated learning. He divided the self-feedback process into two components: self-judgment which links itself to the evaluation of performance and results and self-reaction which involves the satisfaction with the result of the effort put into the process and adaptive conclusions as the results of changes which are necessary to alter the self-administrative approach during the following effort making during the learning and students performance. On the other hand, researchers such as A. H. Schoenfeld (1985), describe monitoring as a key attribute of the problem solving process and also as a basic component for the successful accomplishment of the task. Feedback (evaluation and assessment) and monitoring, as described by G. Schraw (1998) belong to the so called metacognitive strategies (with planning processes as well) and as a result of this, metacognitive strategies stand right at the beginning of the metacognition (Flavell, 1976), we can therefore conclude that theoretical experts are pointing out metacognitive strategies and the main component, throughout which metacognition develops. Contemporary findings resulting from effectivity of strategy teaching researches are showing that children do not sufficiently monitor the effectivity of their learning strategy usage, they can be, however, taught to do so (Schneider - Pressley, 1997).

The most important factor for the metacognition development is probably the qualitative changes during the young adolescence period of human life. Experts seem to agree that the older children get, the more they are aware of their own thought processes (Flavell, 1978). This ability progresses over years and it is mostly overt during exercise making which requires the use of more advanced strategy application. On the other hand, even 6-year-old children are quite accurate in reflecting their own cognition especially when they are doing a task which is familiar to them (Flavell, 1992). Even among children going through the first few years of elementary schools we can observe the relationship between the level of metacognitive development and the performance in math subjects (Rottier, 2003) and therefore successful training of metacognitive strategies can be successfully applied even within this age group (Mevarech, 1995). Previous J. Piaget's model has been already partially revised. The ability to not only applying cognitive though operations towards a certain object but also the mental

${ }^{1}$ Autoregulated learning can be characterized as a certain gained level of students mentality in which it takes the role of an autonomous aspect of the learning process (Skoda - Doulik, 2011), translated by (Rudorfer, 2015) 
ability to perform certain actions towards this object, are the preconditions for metacognition itself. An assumption that children, before engaging in formal thought operations, are not able to develop their metacognitive abilities has been already disproven based on the argument that the development of cognitive structures does not take place only during growing up, but also during learning (Kohoutek, 2008). This paradigm is supported by longitudinal studies. The notion, that children develop strategic thinking gradually, is now disproved. B. Sodian a W. Schneider (1999) focused their analysis of subject organization strategy development based on the data remembering from the Munich longitudinal study of individual development. This study shows that the data, which had been collected for about 2 years, proved unsatisfactory results, where children showed either absolutely no strategy use whatsoever, or a great skill in using it. This pattern of a sudden shift in strategy use in information organization was more (Schlagmüller \& Schneider, 2002) or less (Kron-Sperl - Schneider - Hasselhorn, 2008) discussed in other studies. A satisfying explanation for this dramatic shift hasn't been fully uncovered. Contemporary researches also examine preschool children during the so-called "pre-operational stage" (Kron-Sperl, Schneider - Hasselhorn 2008). We feel that it is important to point out, that depite that some results (Schneider, 2008) indicate direct proportionality between age and the development of declarative metacognitive knowledge or the ability. However, when discussing the ability to control cognitive tasks, we can conclude that the proportionality between these phenomena is not as directed as previously mentioned. Simply speaking, the development of metacognition, as well as the problem solving processes doesn't proceed in a linear way (Azevedo, 2009).

\section{The development of metacognitive strategies}

Within the question of the strategy development the research has shown that the learning tasks have to be adequately difficult and stimulating, so the student uses metacognitive strategies in a particular way. In detail, this means that the application of metacognitive knowledge brings benefits only if the learning tasks are placed within a subjectively intermediate range of difficulty (Neuenhaus, 2011), due to which the requirements of teachers increase. It seems like an unbelievable burden for a teacher to create testing methods which would be equal for all students on the intermediate level of difficulty, however point of view of the contemporary paradigm of individualization of education votes in favor of this notion. We have to know which strategy does a student use and how advanced is his/her ability to generalize these strategies influenced by metacognitive and associative processes. Apart from the strategy training, a teacher should be able to focus even on metacognitive knowledge without which, (even though the training might be successful) the learned behavior may vanish on its own quite soon after an individual is no longer exposed to the educational context. Without early educational interference and metacognitive awareness activation, active systematic use of strategies takes years before it starts to develop (Waters Schneider, 2009). 
When children in 1 st grade were asked to remember 16 pictures, this seemed like a quite difficult task for such young age (6-7 years of age in Czech Republic). Children had problems to connect and recall the suggested strategy introduced prior to the task itself. They mostly had trouble to remember pictures according to the category they belonged to. On the contrary, children, who had to remember only 8 pictures (which are considered a simple task suitable for such age), had no major difficulty in working with adequate cognitive sources in order to remember the strategy of categorization, which in this case children did and were even aware of it. The use of metacognitive strategies is determined by the context of learning environment. The metacognitive strategy training is therefore completely impossible to apply in the so called "context vacuum", meaning the environment without any information content to be learned. Research within this area is determined by the hypothesis of children influencing their knowledge by the selection of specific strategies during the learning process (e.g. Brown, 1978). It is also stated, the deeper knowledge children gain about memory processes, the better their knowledge allows them to monitor effectivity during strategy training and in case of the necessity to change their techniques in order to remember certain data.

Intentional intervention of autoregulated (metacognitive) skills takes place more often among the secondary level of education (middle schools). Not only children before attending middle-schools, but also 9th graders in elementary schools work with this skill (Hrbackova, 2011). We can observe spontaneous manifestations of autoregulation and metacognition. This can offer space for educators to apply intentional intervention. To support this concept we can find empirical evidence in recent research of pre-school children done by K. Hrbackova (2009). The result was that pupils with higher level of reading skills were statistically better in the metacognitive score. Meta-analysis of 48 case studies (Dignath - Buttner, 2008) points out that the highest effectivity of metacognitive strategy training is in correlation with strategy of planning - monitoring and evaluation. The teachings of one or three of these strategies were previously rather less effective. Correlation studies on the level of metacognitive strategy a strategy use connections quite surprisingly show more or less inconsistent results (Waters and Schneider, 2010). Correlations seem to be quite poor for our research and they also fluctuate in time. This phenomenon points out a fundamental assumption stating, in the relation between metacognitive knowledge and its use are more variables interfering with the results, these variables contain child's motivation to do a certain task, the nature of the task itself, connection of the task to the age of the solver and also measuring methods which may also interfere. Nevertheless, W. Schneider and M. Pressley (1997) discovered in their analysis, containing 60 completed studies, correlation of 0,41 between meta-memory and strategy use. It is therefore necessary to keep in mind this is a two-way connection of the way we perceive and understand our memory processes and how they influence our strategic learning and therefore the strategy application contributes to better understanding of our memory processing (Borkowski - Carr - Rellinger - Pressley, 1990; Kuhn, 1999). This also leads to the bipolarization of the research intentions. While some of 
the researchers focus on knowledge through the memory processing of the students (Fritz - Howie - Kleitman, 2010), others (Luwel - Torbeyns Verschaffel, 2003) measure gained knowledge of students through inner learning strategy approaches. Despite of the relations of the metacognitive components between each other, W. Schneider (2009) presents a list of studies which were focused on these relations previously mentioned. From the results we can conclude, all upper mentioned factors have not only a significant impact on children in early school years, but they also determine their performance in math, reading and comprehension of older schoolattending children which is also very significant, regardless of intellectual skills of individual pupils/students.

One of the more interesting and efficient approaches was introduced by A. S. Palincsar and A. L. Brown (1984), an approach which was tested on older elementary school students. Teachers and students applied reading strategies step-by-step then these strategic processes were incorporated during the class and uncovered during open discussions. During this approach strategies were openly and well explained and demonstratively modeled with the possibility to try out these techniques during the whole course with a lot of classes. The goal was to help children discover the helpfulness and benefits of reading strategies and also to make teachers pass the notion of usefulness of these strategies and information of when and where is a concrete example of a strategy good to use. Educators who use the principle of reciprocal teaching were more aware of their responsibilities during strategy implementing during teaching, especially at the beginning of a class, after some time they were able to pass the control to their students so they could later regulate their own process (Palincsar, 1986).

One of the ambitious programs, with the aim to systematically evaluate the effectivity of the metacognitive knowledge teaching in the educational system, could be those study programs in which teachers regularly implemented the selection of effective strategies and adapting to them as a part of everyday curriculum. We need to point out an important fact: strategies were not excludly isolated, but were integrated into the curriculum and lectured as a part of the foreign language courses, math courses, natural and social science courses. Also other authors (Artelt - Schiefele - Schneider, 2001; Mevarech - Kramarski, 1997, 2003) referred to the findings where: effective teachers didn't promote just one strategy, but taught a flexible was of different solutions to individual task, paying respect to their specialization, time management, other requirements of individual tasks etc. Among most of the examples, the strategy teachings took place when students were divided into small groups and the teacher demonstrated the suitable strategy use.

The research demonstrably show that the skill in the strategy use develops with age, as well as the ability of record and recall information. For example when pupils were given a chart of three objects to remember: a table, a car and a flower, older children are able to repeat the words table, table, table when they see the first picture; table, car, table, car when they see the second one, and table, car, flower when they see the final one, unlike younger children who repeat the same word three times over table, table, table when they thee the first picture, car, car, car during the other, and flower, flower, 
flower when they see the final picture. The important fact here is the differences in training have a huge impact on the remembering process, where older individuals are more active during the training and their information recalling process is dramatically enforced especially among previously presented stimuli on the chart (Ornstein - Naus - Liberty, 1975). This ability, which develops growing up is much more overt during task completing, which involves more complicated strategy choices than just simple revising of previous information. During a certain task, where students are asked to "put together a group of terms in order to remember them better" we can rarely witness students of $3^{\text {rd }}$ or $4^{\text {th }}$ grade of primary school the ability to put together terms into categories, based on their semantic referential similarities. However, $6^{\text {th }}$ grade students and adults are quite skilled in this particular task, even though no task instruction is given to them prior to the activity. (Ornstein - Trabasso - Johnson-Laird, 1974). Many studies show, children of younger school age are aware of semantic term similarities and relationship between words and especially when terms are difficult to be put in order. This concludes the most effective way of the strategy use doesn't result from the lack of strategy knowledge of how to put terms together, but from the inability to use gained knowledge strategically. One of many reasons why younger students fail in the strategy use may be insufficient cognitive sources of attention. This lack of a source can be compensated during active strategy training followed by a visual access to the trained material, or teachers can structuralize the trained tasks for children. (Best - Ornstein, 1986). We can observe older children tend to use a much wider repertoire of strategies which are helping them with remembering. During the process of aging, children are able to avoid the use of less effective strategies suitable for a certain situation. This means, even though younger children have the advantage of possessing procedural and conceptual memory during strategy use, they are still unable to actively contribute to the lessons due to the lack of experience and effort which individual learning tasks require (Guttentag - Ornstein - Simens, 1987). In some of these cases, children can be led by a teacher, who is able to streamline their center of attention to the organization of material with the use of an explanation, object lesson, or by any means of visual instruction.

To be specific, there is much more of unused potential for metacognitively oriented lectures and teaching focused on everyday students teaching (Schneider, 2009). Even though there seems to be absence of a bigger amount of empirical proof, general theoretical outcomes give a big role to the correlation of two components of metacognition (metacognitive knowledge and metacognitive monitoring), which both contribute to the school performance. Successful managing of the learning situation and longterm performance-based development comes mainly from the simultaneous work of these two interacting components. If metacognitive knowledge is well prepared to be used, it can influence the quality of the monitoring process itself. The main job of the metacognitive monitoring is to recognize suitable opportunities for metacognitive knowledge use. Specifically, the development of strategic learning regulation is taking place only under the condition, where a teacher is able to recognize (throughout metacognitive 
monitoring) a good opportunity to effectively use metacognitive knowledge (Neuenhaus, 2011).

\section{Contemporary trends in metacognitive strategy research}

Experts are still not sure, whether the teaching should be focused on mainlyspecific knowledge and skills or whether to teach general facts of variety of special focus in order to help students apply themselves on the job market in their preferred specialization. (Waters - Schneider, 2009). Even though the second mentioned option is, pedagogically speaking, better, educational methods during problem solving teaching are applied in the more specific areas thank to the much more reliable results and avoiding the problems with transferring the knowledge between domains, which has other obstacles in the way that there is not much better option (Chi - Glasser - Farr, 1988). For illustration, try to imagine a specialist in the organic chemistry area, who will be given a problem solving task from the political science area. This specialist failed in all attempts to solve any kind of problem outside his domain. On the other hand, some experts argue, (Siegler - Alibali, 2005) certain levels of domain-general processes are essential for the function of other domain-specific processes. R. S. Siegler, M. W. Alibali (2005) provide their interpretation of the problem stating, learning effective skills how to solve particular problems is simultaneously taking place on many levels: domain-specific and domain-general. Be that as it may, differences in the domain-general and domain-specific strategy use can be observed depending on the age of the problem solver, his/her experience with the given task etc. Within various different tasks, approaches of each expert towards problem solving were examined - these tasks involved the recognition of several bird species. Several experts with different specialization, age and general education were asked to solve these tasks. Even though selected individuals with an expert knowledge in their field of expertise were able to outrun university students without any experience so far, differences between the experts were very apparent. The most significant difference was spotted in a particular task, in which a close Yes/No question were given in order to identify a specific bird species which the experimentation had in his catalogue. A young expert, as well as a beginner expert couldn't use equally effective strategy during questioning, and as well as the expert, who had much more experience in his academic field and therefore much more experience with different types of test templates weren't able to solve this particular task. From these observations we can conclude that the applying of domain-general strategies contributes to the more effective use of domainspecific strategies. The question here is not which domain has to be preferred over the other, but rather how to help student's different information integrate in their strategic knowledge in order to be able to use them in certain situations. It is more than important to keep in mind that individuals differ not only in their knowledge but also in the ways how each of them use particular knowledge.

Contemporary scientific works are focusing on metacognitive strategies which differ from each other based on the specific domain where they are applied (critical reading, math, history, biology etc.). Generally we can 
perceive two phases of metacognition which contribute to the student's success during task solving. The first phase contains the successful and accurate understanding of a specific task/question and recognizing this information, the second phase consists of finding the right solution to the problem and its correct applying. In the first example we can link the ability to the metacognitive strategies that lead to the problem solving, so called "comprehension strategies", which are followed by "problem solving strategies" themselves. Student needs to gain necessary information about the test question/task and be able to understand it properly, comprehend and figure out where the problem is and what is required from him/her to do in order to succeed. In the second phase we manipulate with the possibilities of potential solutions and their results. These two components are being represented during each task/question, regardless of the domain. The conclusion here is simple: both components are the key to successful task solving.

\section{Reading strategies}

According to the contemporary researches, a skilled reader is still not characterized by the set of rigidly bordered meta-cognitive strategies or by the knowledge of a wide variety of these strategies (El-Koumy, 2004). As the main argument here may be the ability to use flexibly the disposable strategies depending on a specific context. In the relation to the educational process we can therefore primarily speak of specifics of a certain educational subject.

C. E. Snow, M. S. Burns and P. Griffin (1998) profile the so called skilled reader as an individual who is capable of comprehendig a read text thanks to his ability to "use their general overview in order to comprehend words in the text by inferring from the message in the text and using this monitoring of their own comprehension and correcting strategies in some cases, when they realize they don't completely understand the text." (1998: 62). Experts in reading comprehension agree that skilled readers differ from unexperienced ones in the way they are aware of what they are reading in the process, and also why they are reading it - therefore they possess plans and strategies how to deal with obstacles during reading. B. B. Arnbbruster, C. H. Echols and A. L. Brown (1983) agree with this. They also point out the ability of skilled readers to adapt in a flexible manner their strategies of a reader on actual situation and requirements. These readers are also aware of how to monitor information comprehension and when an obstacle occurs, they are able to react on changes by changing their strategy (Pressley - Afflerbach, 1995). Skilled readers also perceive reading process as an activity connected to the search of meaning (Garofalo -Lester 1985).

Less skilled readers are more likely to concentrate on lexical meaning of the words within the meaning and they understand the reading comprehension process as a message decoding process (Baker - Brown, 1984), these readers are therefore limited in their metacognitive knowledge use in the field of reading knowledge (Paris - Winograd, 1990) and are likely to less monitor their comprehension (Flavell, 1979). These readers also tend to overlook 
contrasting information within the text, or they are not able to explain any kind of uncertainty.

Reading strategies can (and should) be taught until the moment of automation, when a repeated strategy becomes a imprinted set of skills and students know, which strategy to choose and when is it useful to apply them (Paris - Lipson - Wixon, 1983). Many experts pointed out the fact strategic reading can be taught easily by a set of prepared classes (Brown, Armbruster, \& Baker, 1986). S. G. Paris a P. Winograd (1990) however highlight „,metacognition should not be perceived as the final goal of any learning or teaching. ", but the opposite, metacognition should be perceived as the opportunity to "help pass the knowledge and certainty on students, which will help them to enforce their enthusiasm and seeking for possibilities in their goals, which they are willing to pursue. " (1990: 22).

\section{Problem solving strategies}

Learning of strategies towards problem solving seems greatly important for the development of metacognitive skills dealing with mathematical tasks. Even though declarative metacognitive knowledge does precede and help metacognitive procedural knowledge, especially verbal skills (Grimm, 2008) and conceptual mathematical knowledge (Chi, 1992), can change the development of metacognitive skills and this way help to effectively solve mathematical tasks and exercises. Researchers aim their interest at the development of effective approaches, learning strategies, intentional interventions for children mathematical concept development, problem solving skills etc. Contemporary approaches point out ways in which students gain mathematical knowledge and how does this connect to the metacognition itself.

L. A. Brown and A. S. Palinscar (1982) describe three types of strategy training:

a) Blind training (instructs students to use a certain strategy; however students are not led to the understanding of its significance. Students are simply told "what to do", but not "why and under what circumstances they have to do so" ; The research results suggest that students are not able to hold strategies in their long-term memory or even to generalize all learned strategies)

b) Informed training Combines instruction and inner manipulation with strategies with the process of giving information about the significance of a chosen strategy

c) Auto-regulatory training Includes elements of metacognition. During the strategy training, students are introduced to the significance of a given strategy. The whole process is accompanied by planning, monitoring and evaluation of the selected strategy.

Even though an informed training seems to be more effective than the bling training method, the auto-regulatory training shows success. Very common way of teaching mathematics however is specific by the way of leading children to memorizing the mathematical procedures. There is a variety of researches among many specializations which show this approach does not work. Firstly, when a student learn specific mathematical procedure, it does 
not mean, he/she knows why and when to use the procedure (O'Sullivan Pressley, 1984). Not only that, routine repeating of procedures leads to the misunderstanding of many students. They simply do not understand why should they adapt and use their knowledge during situations, when they will need them (Pressley - Harris - Marks, 1992).

Contemporary pedagogical experiments repeatedly prove that the development of metacognition is done through teachings based on problem solving (Downing - Kwong - Chan - Lam - Downing, 2009). The first empirical observations were made on the beginning of the 1980s, when F. K. Lester a J. Garofalo (1982) managed to show the fact that primary school children generally do not analyze the problem situation and information that it contains, pupils do not monitor their own progress and do not even evaluate their results. Even some amount of university students has an insufficient level of these abilities (Garofalo - Lester, 1985). S A. L. Brown and S. S. Smiley at the end of the 70s (1977) discovered; students spontaneously do not make notes during classes or do not apply the textbook underlining strategy. If they will be led to this approach in the Framework of intentional intervention, they are more likely to apply these strategies by themselves more than students, who used these strategies spontaneously at the beginning; however they have not undergone the intentional intervention. S. G. Pairs a P. Winograd (1990) state: "students can improve their learning by realizing their own thoughts during their reading, writing or problem solving thought processes. Teachers can support this awareness too by informing students about the problem solving strategy effectivity and by discussions about cognitive and emotional thought characteristics" (1990:15). Majority of students from $3^{\text {rd }}$ and $5^{\text {th }}$ grades are convinced that the length and amount of numbers in the math exercises are the main indicators of difficulty among these exercises (Lester - Garofalo, 1982), meaning that on the basis of learning the key words it is possible to define required mathematical operations and that the exercise can be solved by a direct application of one or more arithmetical operations

J. Garofalo and F. Lester (1985) preferred the metacognitive monitoring and evaluation in their work. Monitoring and evaluation help during the effective mathematical strategy use. Researchers thought the most important form of managing these processes during classes is the selection of the educational frame, in which the general problem solving can be, implemented (e.g. Cognitive-Metacognitive Framework for Studying Mathematical Performance). J. Garofalo and F. Lester created four activity categories which are represented during mathematical task problem solving: orientation, organization, execution, verification. The significance of this division comes from the fact which states: metacognitive tasks are more likely to occur during a certain phase depending on the nature of the mathematical task. In order to acquire this general approach, we have to keep in mind the application of this model has to be used in various curriculum systems; we also need to use variety of metacognitive tasks and learning techniques implemented into the metacognition in math Framework. (Garofalo - Lester, 1985). That same age group of students thought that an individual who is good at mathematical operations can be determined by the amount of 
exercises that certain individual makes every day. Also they thought that in order to solve word-based mathematical problem, individual needs more time to solve it and rushing may cause an error in progress.

The connection between a successful problem solving and metacognition has been quite well documented in literature over the past twenty years (e.g. Montague - Applegate, 1993; Carr - Biddlecomb, 1998), and also the intentional training of metacognitive strategies is therefore well documented in the area of math class performance improvement, containing data concerning the abilities of solving mathematical problems. We can analyze these aspects among older primary school children (Riley, 2000) and younger primary school pupils (Hubert, 2011). J. Hattie and colleagues (1996) created a meta-analytic study and came up with the conclusion; the impact of intentional intervention is higher among first graders of primary school up till the 5th graders than among older students or even high-school students or university students. Other meta-analysis (Dignath - Buttner, 2008) suggests positive impact of intentional intervention on the younger pupil's performance in mathematics (much higher than older primary school children), on the other hand the impact of intentional intervention among older children was significant during reading or writing assignments (again, much higher than younger primary school children). Current research examined many teaching techniques which support mathematical comprehension as a contrasting factor to memorizing approach in mathematical problem solving. Key methods are therefore those, which were described by M. Carr (2010) in her work as explicit instructions, justification and social interaction. The author explains; even though students learn effectively when they actively look for information and generate their own notes, there is no empirical research or record that would show it is necessary for students to create their own metacognitive strategies independently on the teacher's guidance. These strategies can be taught directly by the educator explicitly. In addition to this fact, declarative knowledge of metacognitive strategies increases the opportunity for students to construct their own effective strategies and test their usefulness. Many students gain declarative and procedural metacognitive knowledge through social interaction with their schoolmates and friends, parents and teachers. On the other hand, many students start attending school with much deprived knowledge of metacognition. The reason for this is that students do not consult their metacognitive procedures (how they think about their learning) with anyone, neither at home nor at school. Especially students with poor school performance and low grades, or with specific learning disorders, who usually are not given the opportunity to build up their knowledge with the help of social interaction at home or school, need to build their declarative metacognitive skills explicitly (Montague, 1992). There are fears of explicit education may slightly decrease its standard to mere memorizing of mathematical procedures. And yes, these fears are justified, however during metacognitive knowledge education and taking action slowly and step-bystep, student will not only gain higher comprehensive skills, but also manifest 
skills of using their gained knowledge during new, previously not known, mathematical tasks.

The process of strategy acquisition is not a linear one. Authors such as M. Pease and D. Kuhn (2011) suggested and empirically examined their hypothesis f knowledge acquisition for effective strategy use during problem solving tasks. Their analysis shows the acquisition of effective strategy is not only the question of learning and using a particular strategy but it is more closely connected to two different thought processes. Firstly, less suitable and learned (any mostly automatically learned) approaches towards certain solutions have to be repeatedly attached to the active thought processes and at the same time elaborated and processed. Between these two processes we need to make a distinction, because Kuhn and Pease mentioned both of them having their own role during task problem-solving and also these both aspects have different development during acquisition. Two different processes can also reflect the dual-process information processing theory (Evans, 2003), whereas inhibition of strategies depends on a fast heuristic system. The effective strategy acquisition requires an analytic approach and the willpower to make it happen. On the other hand, this hypothesis hasn't been fully validified by researchers and still need more empirical data. Much more beneficial differentiation of these processes was demonstrated on the influence of social environment, where inhibition of less efficient strategies takes place much more often during interaction with other individuals, whereas the acquiring of adequate strategies is not influenced by the social aspect as much as previously mentioned.

\section{Conclusion}

Quite significant discovery within our field of interest of metacognitive strategies is the conclusion stating metacognitive strategies can be determined and learned. This specific ability is possible to learn and develop via systematic and intentional training (Schraw, 1998). Studies over last 25 years have shown how to gain, store and recall knowledge of our memory. The levels of metacognitive development are therefore a strong precondition to the school successful performance. The ability to think clearly and accurately which involves strategies of thinking in order to comprehend and understand terms and being able to individually examine and analyse any aspect, is, therefore, quite significant feature of child's education. It does not matter what subject is being learned by the child, when the individual does not know what is wanted from him/her, or if the individual is not capable of recognition and solution of problems that he/she has to deal with prior to this experience, these individuals cannot develop in this way at all (Fontana, 2003). We agree to a large extend with M. E. Sarver (2006) stating ,....main responsibility of teachers is not dispensing of knowledge and no teacher is capable of teaching their students everything, which they will need in real life. A teacher is capable to equip students with autoregulation strategies which will provide them with essential techniques and approaches in order to become independently thinking creatures with lifelong teaching ability"( $p$. 221) 
Experts agree that parents can help their children with their cognitive development by improving their metacognition (Ornstein et al., 2010). Scientific studies have already made a great progress in this area, however studies insist on the fact that there is still a lot of hidden potential for improvement of the educational process. Despite of the applying of metacognitive strategy teaching during classes, it is rather difficult to do so and there are only few studies focusing on effectivity of intentional intervention in natural environment during school classes. We are rather optimistic at this moment and we do believe this particular area will develop quite rapidly in the future. If not in Czech Republic, there is a variety of training programs abroad focused mainly on metacognitive thinking skills. Regular interventions guarantee the long-lasting effect and positive impact on children (Schneider - Pressley, 1997). We are convinced, the regular training, thanks to which students will understand the relevance of metacognition skill building holds the key to help students make the effort towards this development. Schneider (2009) comes up with a warning, stating “...the main condition of applying of metacognitive-oriented teaching is the increase of comprehension of conceptual effective learning basics among teachers. It will be difficult to uphold this approach, unless teachers will learn to think in terms of cognitive psychology." (p.74). at the same time we see the need to show more empirical proof in order to apply this approach in Czech curriculum. The use of metacognitive training is still somewhat unusual feature in schools simply because of a few reasons: first of all, there seems to be poor awareness or inadequate pre-gradual training of future educators in these issues and secondly, researches in this field of interest take place in controlled laboratory environment. The following transfer connected with result applying seems therefore rather not very compatible with the educational reality in practice. We still have hope educator's metacognitive thinking won't be a unique phenomenon (Duchovicova, 2010) in the near future.

\section{Bibliography}

ARTELT, C. - SCHIEFELE, U. - SCHNEIDER, W. 2001. Predictors of reading literacy.European Journal of Psychology of Education, 16(3), pp. 363-383.

ARMBRUSTER, B. B. - ECHOLS, C. H. - BROWN, A. L. 1983. The role of metacognition in fading to learn: A developmental perspective (Reading Rep. No. 40). Urbana: University of Illinois, Center for the Study of Reading. AZEVEDO, R. 2009. Theoretical, conceptual, methodological, and instructional issues in research on metacognition and self-regulated learning: A discussion. Metacognition and learning, 4, pp. 87-98.

BAKER, L. - BROWN, A. L. 1984. Metacognitive skills and reading. In D. Pearson, M. Kamil, R. Barr, P. Mosenthal (Eds.), Handbook of Reading Research. New York; Longman. pp. 353-394.

BEST, D. L. - ORNSTEIN, P. A. 198. Children's generation and communication of mnemonic organizational strategies. Developmental Psychology, 22(6), 845. 
BOEKAERTS, M. 1997. Self-regulated Learning: A New Concept Embraced by Researchers, Policy Makers, Educators, Teachers, and Students. Learning and Instruction, 7(2), pp. 161-186.

BORKOWSKI, J. - CHAN, L. - MUTHUKRISHNA, N. 2000. A ProcessOriented Model of Metacognition: Links Between Motivation and Executive Functioning. Issues in the Measurement of Metacognition.

BORKOWSKI, J. G. - CARR, M. - RELLINGER, E. - PRESSLEY, M. 1990. Self-regulated cognition: Interdependence of metacognition, attributions, and self-esteem. Dimensions of thinking and cognitive instruction, 1, pp. 53-92.

BROWN, A. L. 1978. Knowing when, where and how to remember. A problem of metacognition. In. R. Glaser (Ed.), Advances in instructional psychology (Vol. I). Hillsdale, NJ: Erlbaum.

BROWN, A. L. - ARMBRUSTER, B. B. - BAKER, L. 1986. The role of metacognition in reading and studying.Reading comprehension: From research to practice, pp. 49-75.

BROWN, A. L. - SMILEY, S. S. 1977. Rating the importace od structural units of prose passages: A problem of metacognitive development. Child and Development, 48, pp. 1-8.

CARR, M. 2010. The importance of metacognition for conceptual change and strategy use in mathematics. In H. S. Waters, W. Schneider (Eds.), Metacognition, strategy use, and instruction. New York: The Guilford Press, pp. 176-197.

CARR, M. - BIDDLECOMB, B. 1998. Metacognition in mathematics from a constructivist perspective. In D. J. Hacker, J. Dunlosky, A. C. Graesser (Eds.), Metacognition in educational theory and practice. Mahwah, NJ: Lawrence Erlbaum Associates, pp. 69-91.

CHI, M. 1992. Conceptual Change Within and Across Ontological Categories: Examples From Learning and Discovery in Science. In R. Giere\& H. Feigl (Eds.), Cognitive Models of Science Vol. 15. University of Minnesota Press, pp. 129-186.

CHI, M., Glaser, R., \& Rees, R. 1982. Expertise in problem solving. In: Sternberg, R. J. (Ed.), Advances in problem solving Vol. 1, Hillsdale, NJ: Lawrence Erlbaum, pp. 7-75.

CAP, J. - MARES, J. 2001. Psychologie pro ucitele. Praha: Portal.

DIGNATH, CH. - BUTTNER, G. 2008. Components of fostering selfregulated learning among students. A meta-analysis on intervention studies at primary and secondary school level. Metacognition and learning, 3, pp. 231264.

DOWNING, K. - KWONG, T. - CHAN, S. - LAM, T. - DOWNING, W. 2009. Problem-basedlearning and the development of metacognition. High Education, 57, pp.609-621.

DUCHOVICOVA, J. 2010. Neurodidakticky a psychodidakticky kontext edukacie. Nitra: PF UKF. ISBN 978-80-8094-783-5

EL-KOUMY, A. S. A. K. 2004. Metacognition and reading comprehension: Current trends in theory and research. Cairo: Anglo Egyptian Bookshop.

EVANS, J. S. B. 2003. In two minds: dual-process accounts of reasoning. Trends in Cognitive Sciences, 7(10), pp. 454-459. 
FONTANA, D. 2003. Psychologie ve skolni praxi: Prirucka pro ucitele. Praha: Portal.

FLAVELL, J. H. 1992. Perspectives on perspective taking. In H. Beilin, P. Pufall (Eds.), Perspectives on the development of memory and cognition. Hillsdale: Erlbaum, pp. 3-33.

FLAVELL, J. H. 1979. Metacognition and cognitive monitoring: A new area ofcognitive-developmentalinquiry. American Psychologist, 34(10), pp.906911.

FLAVELL, J. H. 1978. Metacognitive development. In J. M. Scadura, C. J. Brainerd (Eds.), Structural process theories o f complex human behavior. Alphen a. d. Rijn. The Netherlands: Sijthoff and Noordhoff.

FLAVELL, J. H. 1976. Metacognitive aspects of problem solving. In L.B. Resnick (Eds.), The nature of intelligence. Hillsdale, NJ: Erlbaum, pp. 231235.

FRITZ, K. - HOWIE, P. - KLEITMAN, S. 2010. How do I remember when I got my dog? Thestructure and development of children's metamemory. Metacognition and Learning, 5, pp.207-228.

GAROFALO, J. - LESTER, F. 1985. Metacognition, cognitive monitoring, and mathematical performance. Journal for Research in Mathematics Education, 16(3), pp.163-176.

GAVORA, P. 2010. Aki su moji ziaci? - Pedagogicka diagnostika ziaka. Nitra: Enigma.

GUTTENTAG, R. E. - ORNSTEIN, P. A. - SIEMENS, L. 1987. Children's spontaneous rehearsal: Transitions in strategy acquisition. Cognitive Development, 2(4), pp.307-326.

GRIMM, K. J. 2008. Longitudinal Associations Between Reading and Mathematics Achievement. Developmental Neuropsychology, 33(3), pp. 410-426.

HABL, J. 2012. Pedagogy and Metanarratives: Educating in Postmodern Situation. E-pedagogium, 12(4), pp. 84-93.

HATTIE, J. - BIGGS, J. - PURDIE, N. 1996. Effect of Learning Skills Interventions on Student Learning: A Meta-Analysis. Review of Educational Research, 66(2), pp. 99-136.

HELUS, Z. - PAVELKOVA, I. 1992. Vliv zaku ke vzdelavaci autoregulaci a humanizaci skoly, Pedagogika, 42(2), pp.197-206.

HRBACKOVA, K. 2011. Vliv metakognitivní intervence na rozvoj mysleni deti predskolniho veku. E-Pedagogium, 2011(3), pp. 49-63.

HRBACKOVA, K. 2009. Autoregulace procesu ctenarskeho rozvoje zaku na 1. stupni zakladni skoly. Pedagogická orientace, 19(4), pp. 74-91.

HUBERT, W. C. 2011. The Impact of Reciprocal Teaching on Mathematics Problem Solving for Grade 4 Students (Doctoral dissertation, Central Connecticut State University, USA). Retrieved from: http://elibraryusa.state.gov.

INGACIO, G. N. - NIETO, B. J. L. - BARONA, G. E. 2006.The affective domain in mathematics learning. International Electronic Journal of Mathematics learning, 1(1), pp.16-32.

KOHOUTEK, R. 2008. Kognitivni vyvoj deti a skolni vzdelavani. Pedagogicka orientace, 18(3), pp. 3-22. 
KRON-SPERL, V. - SCHNEIDER, W. - HASSELHORN, M. 2008. The development and effectiveness of memory strategies in kindergarten and elementary school: Findings from the Würzburg and Göttingen longitudinal memory studies. Cognitive Development, 23(1), pp.79-104.

KUHN, D. 1999. A developmental model of critical thinking. Educational researcher, 28(2), pp. 16-46.

LAI, R. E. 2011. Metacognition: A literature Review. Retrieved from: www.pearsonassessments.com.

LESTER, F. K. 1978. Mathematical problem solving in the elementary school: Some educational and psychological considerations. In L. L. Hatfield, D. A. Bradbard (Eds.), Mathematical problem solving: Papers from a research workshop (pp. 53-87). USA: Columbus, $\mathrm{OH}$.

LESTER, F. K. - GAROFALO, J. 1982. Metacognitive aspects of elementary school students' performance on arithmetic tasks. Paper presented at the meeting of the American Educational Research Association, New York.

LUWEL, K. - TORBEYNS, J. - VERSCHAFFEL, L. 2003. The relation between metastrategic knowledge, strategy use, and task performance: Findings and reflections from a numerosity judgement task. European Journal of Psychology of Education, 18(4), pp. 425-447.

MEVARECH, Z. R. 1995. Metacognition, general ability, and mathematical understanding. Early Education and Development, 6(2), 155-168.

MEVARECH, Z. R. - KRAMARSKI, B. 2003.The effects of metacognitive training versus worked-out examples on students' mathematical reasoning.

British Journal of Educational Psychology, 73(4), pp. 449-471.

MEVARECH, Z. R. - KRAMARSKI, B. 1997. Improve a multidimensional method for teaching mathematics in heterogeneous classrooms. American Educational Research Journal, 34(2), pp. 365-394.

MONTAGUE, M. 1992. The effects of cognitive and metacognitive strategy instruction on the mathematical problem solving of middle school students with disabilities. Journal of Learning Disabilities, 25(4), pp. 230-48.

MONTAGUE, M. - APPLEGATE, B. 1993. Middle school students' mathematical problem solving: An analysis of think-aloud protocols. Learning Disabilities Quarterly,16, pp. 19-32.

NEUENHAUS, N. 2011. Metakognition und Leistung: Eine Längsschnittuntersuchung in den Bereichen Lesen und Englisch bei Schülerinnen und Schülern der fünften und sechsten Jahrgangsstufe (Doctoral dissertation, Universität Otto-Friedrich, Bamberg, Germany). Retrieved from: http://opus4.kobv.de/opus4/bamberg/frontdoor/deliver/index/docId/327/file/ DissNeuenhausseA2.pdf.

OBAMA hits the road to push for education reforms. 2013. CBS News.Retrieved from:

http://www.cbsnews.com/8301-250_162-57599611/obama-hits-the-road-topush-for-education-reforms/.

OECD, 2013, Education at a Glance 2013: OECD Indicators, OECD Publishing. http://dx.doi.org/10.1787/eag-2013-en. 
ORNSTEIN, P. A. ET AL. 2010. Linking the classroom context and the development of children's memory skills.Handbook of research on schools, schooling, and human development, 42-59.

ORNSTEIN, P. A. - NAUS, M. J. - LIBERTY, C. 1975. Rehearsal and organizational processes in children's memory. Child Development, pp. 818830.

ORNSTEIN, P. A. - TRABASSO, T. - JOHNSON-LAIRD, P. N. 1974. To organize is to remember: The effects of instructions to organize and to recall. Journal of Experimental Psychology, 103(5), 1014.

O'SUllivAN, J. T. - PRESSLEY, M. 1984. Completeness of instruction and strategy transfer. Journal of Experimental Child Psychology, 38(2), pp. 275-288.

PALINCSAR, A. S. 1986. The role of dialogue in providing scaffolded instruction. Educational psychologist, 21(1-2), pp. 73-98.

PALINSCAR, A. S. - BROWN, A. L. 1984. Reciprocal teaching of comprehension-fostering and comprehension-monitoring activities. Cognition and instruction, 1(2), pp. 117-175.

PARIS, S. G. - LIPSON, M. Y. - WIXSON, K. K. 1983. Becoming a strategic reader.Contemporary educational psychology, 8(3), pp. 293-316.

PARIS, S. G. - WINOGRAD, P. 1990. How metacognition can promote academic learning and instruction. In B. Jones, L. Idol (Eds.), Dimensions of thinking and cognitive instruction. Hillsdale, NJ: Erlbaum, pp. 15-51.

PEASE, M. A. - KUHN, D. 2011. Experimental analysis of the effective components of problem-based learning. Science Education, 95(1), pp. 57-86.

PIAGET, J. - WEDGWOOD, S. - BLANCHET, A. 1976. The grasp of consciousness: Action and concept in the young child. Harvard University Press Cambridge, MA.

POLYA, G. 1957. How To Solve It: A New Aspect of Mathematical Method. USA: NY, Doubleday Anchor Books.

Retrieved from: http://math.hawaii.edu/.

PRESSLEY, M. - AFFLERBACH, P. P. 1995. Verbal protocols of reading: The nature of constructively responsive reading. Routledge.

PRESSLEY, M. - HARRIS, K. R. - MARKS, M. B. 1992. But good strategy instructors are constructivists! Educational Psychology Review, 4(1), pp. 331.

RILEY, M. 2000. The Effect of Metagognition and Strategy Training Embedded in Cooperative Settings on Mathematics Performance of At-risk Students (Doctoral dissertation, Walden University, USA). Retrieved from: http://elibraryusa.state.gov/.

ROTTIER, L. K. 2003. Metacognition and mathematics during the 5 to 7 years shift (Doctoral dissertation, Illinois Institute of Technology, USA). Retrieved from: http://elibraryusa.state.gov

SARVER, M. E. 2006. Metacognition and mathematical problém solving: Case studies for six seventh grade students (Doctoral dissertation, Montclair State University, NJ, USA). Retrieved from: http://elibraryusa.state.gov/.

SIEGLER, R. S. - ALIBALI, M. W. 2005. Information-processing theories of development. In Children's Thinking (pp. 65-106). Upper Saddle River, NJ: Prentice Hall. 
SCHLAGMÜLLER, M. - SCHNEIDER, W. 2002. The development of organizational strategies in children: Evidence from a microgenetic longitudinal study. Journal of Experimental Child Psychology, 81(3), pp. 298-319.

SCHNEIDER, W. 2008. The development of metacognitive knowledge in children and adolescent. Major trends and implications for education. Mind, Brain, and Education, 2(3), pp. 114-121.

SCHNEIDER, W. - PRESSLEY, M. 1997. Memory Development Between Two and Twenty. Psychology Press.

SCHOENFELD, A. H. 1992. Learning to think mathematically: Problemsolving, metacognition, and sense-making in mathematics. In D. A. Grouws (Ed.), Handbook for Research on Mathematics Teaching and Learning. pp. 334-370. New York: Macmillan Publishing Group.

SCHOENFELD, A. H. 1985. Mathematical problem solving. Orlando, FL: Academic Press.

SCHOENFELD, A. H. 1983. Episodes and executive decisions in mathematical problem solving. In R. Lesh, M. Landau (Eds.), Acquisition of mathematics concepts and processes. USA, NY: Academic Press. pp. 345395.

SCHRAW, G. 1998. Promoting general metacognitive awereness. Instructional science, 26(1-2), pp. 113-125.

SCHRAW, G. - CRIPPEN, K. J. - HETLEY, K. 2006. Promoting selfregulation in science education: Metacognition as part of a broader perspective on learning. Research in Science Education, 36, pp. 111-139.

SKEMP, R. R. 1979. Intelligence, learning, and action: A foundation for theory and practice in education. USA: Wiley New York.

SNOW, C. E. - BURNS, M. S. - GRIFFIN, P. 1998. Preventing reading difficulties in young children.National Academy Press. Washington DC.

SODIAN, B. - SCHNEIDER, W. 1999. Memory strategy development: Gradual increase, sudden insight, or roller coaster. Individual development from, 3, pp. 61-77.

VEENMAN, M. V. J. - VAN HOUT-WOLTERS, B. H. A. M. AFFENBACH, P. 2006. Metacognition and learning: conceptual and methodological considerations. Metacognition and Learning, 1(1), pp. 3-14.

WATERS, H. S. - SCHNEIDER, W. 2009. Metacognition, Strategy Use, and Instruction. Guilford Press.

ZIMMERMAN, B. J. 2002. Becoming a Self-Regulated Learner: An Overview. Theory into Practice, 2002, 41(2), pp. 64-70.

ZIMMERMAN, B. J. 1995. Self-regulation involves more than metacognition: A social cognitive perspective. Educational psychologist, 30(4), pp. 217-221.

Doc. PaedDr. Pavel Doulík, PhD.

University of J. E. Purkyně in Ústí nad Labem,

Faculty of Pedagogy

České mládeže 8, 40096 Ústí nad Labem

Czech Republic 
pavel.doulik@ujep.cz

Doc. PhDr. Jiří Škoda, Ph.D.

University of J. E. Purkyně in Ústí nad Labem,

Faculty of Pedagogy

České mládeže 8, 40096 Ústí nad Labem

Czech Republic

jiri.skoda@ujep.cz

Mgr. Jaroslav Říčan

University of J. E. Purkyně in Ústí nad Labem,

Faculty of Pedagogy

Hoření, 13, 40096 Ústí nad Labem

Czech Republic

jaroslav.rican@ujep.cz 